\title{
Supramolecular photochemistry. Luminescent and redox active dendritic polynuclear metal complexes
}

\author{
VINCENZO BALZANI, ${ }^{* a}$ GIANFRANCO DENTI, \\ SCOLASTICA SERRONI, ${ }^{b}$ SEBASTIANO CAMPAGNA, ${ }^{c}$ \\ VITTORIO RICEVUTO ${ }^{\mathfrak{c}}$ and ALBERTO JURIS ${ }^{a}$ \\ a Dipartimento di Chimica "G. Ciamician" dell'Università, 40126 Bologna, Italy \\ b Laboratorio di Chimica Inorganica, Istituto di Chimica Agraria dell'Università, 56124 Pisa, \\ Italy

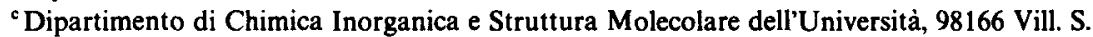 \\ Agata, Messina, Italy
}

\begin{abstract}
The synthetic strategies used to prepare di-, tri-, tetra-, hexa-, hepta-, deca-, trideca- and docosanuclear Ru(II) and/or Os(II) polypyridine-type complexes containing the 2,3-dpp and/or 2,5-dpp bridging ligands and the bpy and/or biq terminal ligands are described (dpp = bis(2-pyridyl)pyrazine; bpy $=2,2^{\prime}$-bipyridine; biq $=2,2^{\prime}$-biquinoline). The light absorption, luminescence, and redox properties of these polynuclear compounds can be varied by changing (i) the nuclearity, (ii) the nature of metal ions, bridging ligands and/or terminal ligands, and (iii) the position of the various components in the supramolecular structure. Because of their strong absorption in the visible spectral region and the possibility of predetermining the direction of energy migration, these compounds can be used as photochemical molecular devices (e.g., as antennas for harvesting solar energy). Because of the presence of several interacting and/or noninteracting redox centres, they are good candidates to play the role of multielectron-transfer catalysts.
\end{abstract}

Keywords. Photochemistry; photophysics; supermolecules; molecular devices.

\section{Introduction}

Supramolecular chemistry has shown that molecular components can be assembled to give species of nanometric dimensions (Lehn 1990; Balzani and Scandola 1991; Schneider and Durr 1991; Vögtle 1991; Whitesides et al 1991; Anelli et al 1992; Balzani and DeCola 1992). Of particular interest are tree-like structures that incorporate in their building blocks specific pieces of information, such as electronic excited states and redox levels at accessible energy values. To pursue this aim, we have designed a synthetic strategy to build up dendritic species based on luminescent and redoxactive transition metal complexes, where desired metals and ligands can be placed in specific sites of the supramolecular structure. Species made of $2,3,4,6,7,10,13$ and 22 metal-based units have already been prepared and larger species can in principle be obtained. This strategy opens the way to the synthesis of species of nanometric dimension capable of harvesting visible light and exhibiting made-to-order patterns for energy and electron migration.

* For correspondence 


\section{Building blocks and bridging ligands}

In the last 20 years extensive investigations carried out on the photochemical and electrochemical properties of transition metal compounds have shown that $\mathrm{Ru}$ (II) and $\mathrm{Os}(\mathrm{II})$ complexes of aromatic diimines, e.g. $\mathrm{Ru}(\mathrm{bpy})_{3}^{2+}$ and $\mathrm{Os}(\mathrm{bpy})_{3}^{2+}(\mathrm{bpy}=2$, 2'-bipyridine), exhibit a unique combination of chemical stability, redox properties, excited state reactivity, luminescence, and excited state lifetimes (Juris et al 1988; Balzani et al 1990; Kalyanasundaram 1991). Furthermore, their properties can be tuned within rather broad ranges by changing ligands or ligand substituents. Several hundreds of these complexes have been synthesized and characterized, and some of them have been used as sensitizers for the interconversion of light and chemical energy as well as for other purposes. Such complexes are ideal building blocks (components) to obtain supramolecular species capable of exhibiting light-induced functions.

In order to assemble such metal-containing building blocks in a supramolecular array, a variety of bridging ligands can be employed. We have concentrated our efforts on the use of the 2,3- and 2,5-bis(2-pyridyl)pyrazine (2,3-and 2,5-dpp) bridging ligands $(\mathrm{BL})$ shown in figure 1.

Some important properties of the $\mathrm{M}(\mathrm{BL})_{3-n}(\mathrm{~L})_{n}^{2+}$ compounds can be summarized as follows (Braunstein et al 1984; Brewer et al 1986; Campagna et al 1989a; Denti et al 1990a): (1) there are intense ligand-centred (LC) absorption bands in the UV region and moderately intense $\left(\varepsilon_{\max } \sim 1 \times 10^{4} \mathrm{M}^{-1} \mathrm{~cm}^{-1}\right)$ metal-to-ligand charge transfer (MLCT) bands in the visible region; (2) a relatively long-lived luminescence $\left(10^{-7}-10^{-8} \mathrm{~s}\right.$ time scale at room temperature) is present in the red spectral region; (3) reversible one-electron oxidation of the metal ion takes place in the potential window $+0.8 /+1.7 \mathrm{~V}$ (vs SCE); (4) reversible one-electron reduction of each ligand takes place in the potential window $-0.6 /-1 \cdot 1 \mathrm{~V}$. Important differences relevant to our discussion are as follows: (i) Os(II) complexes are oxidized at potentials considerably less positive than Ru(II) complexes; (ii) the MLCT absorption and luminescence bands lie at lower energies for the Os(II) complexes than for the Ru(II) ones; (iii) the energy of the LUMO of the (mono-coordinated) ligands decreases in the series bpy $>2,3-\mathrm{dpp}>2,5$-dpp $>$ biq; as a consequence, the lowest (luminescent) ${ }^{3} \mathrm{MLCT}$ level involves the lowest ligand of the above series which is present in the complex; (iv) the electron donor power decreases in the ligand series bpy $>$ biq $\geqslant 2,3-d p p$ $\sim 2,5$-dpp.

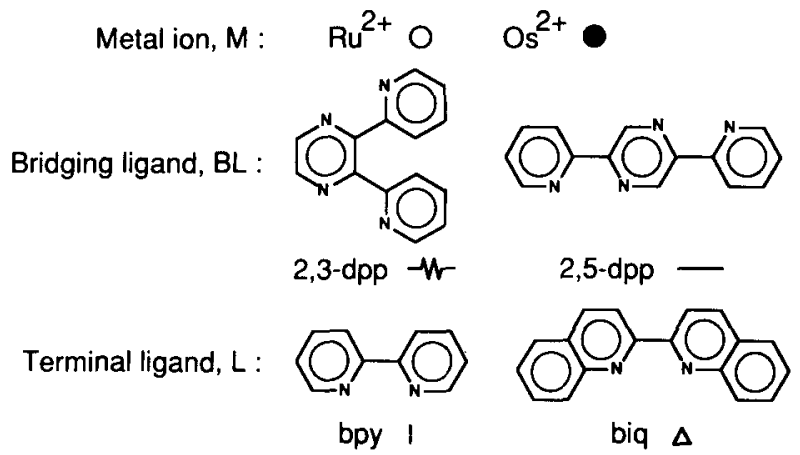

Figure 1. Components of the polynuclear complexes and symbols used. 


\section{Synthetic strategies}

Mononuclear transition metal complexes are synthesized by combining metal ion (M) and free ligands (L), as shown below:

$$
\mathrm{M}+n \mathrm{~L} \rightarrow \mathrm{M}(\mathrm{L})_{n} .
$$

In the last few years we have been developing a procedure to synthesize oligonuclear metal complexes of desired nuclearity and chemical structure (Campagna et al 1989b, 1991, 1992; Denti et al 1990-1993; Serroni et al 1991-1992). Such a procedure is based on the use of complexes (building blocks) in the place of the metal (M) and/or ligands $(\mathrm{L})$ in the synthetic reaction (1). The place of $M$ can be taken by mono- or oligonuclear complexes that possess easily replaceable ligands, and the place of $\mathrm{L}$ can be taken by mono- or oligonuclear complexes which contain free chelating sites ("complexes as metals" and "complexes as ligands" strategy).

Some of the building blocks used in our syntheses are sketched in scheme 1 . The synthetic routes followed to obtain complexes of nuclearity from 10 to 22 are illustrated in table 1 . In each equation, the first reactant plays the role of a metal and the second one plays the role of a ligand. A list of the complexes prepared in our laboratory is also reported in the same table. More details on the synthetic procedures (and on the characterization of the compounds) can be found in the original papers. The final step to obtain the docosanuclear compound is shown in scheme 2.

Schematic views of the decanuclear and tridecanuclear complexes containing 2,3-dpp as a bridging ligand are shown in figures 2 and 3.

As shown in table 1 , the synthetic strategy used is versatile and selective, since the sites occupied by different metals and ligands in the structure of the polynuclear compounds can be synthetically predetermined by the appropriate choice of the building blocks. Recently we have also elaborated a strategy to grow oligonuclear metal complexes in an arborol-like structure according to a divergent approach (scheme 3) (Serroni et al 1992).

"complex metals"

"complex ligands"

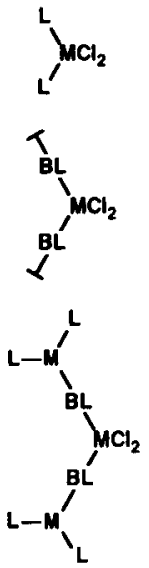

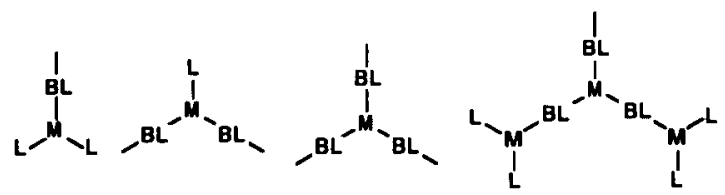

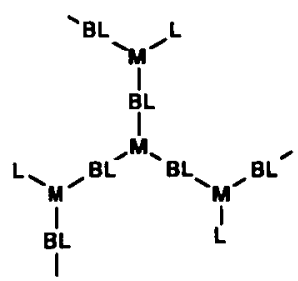

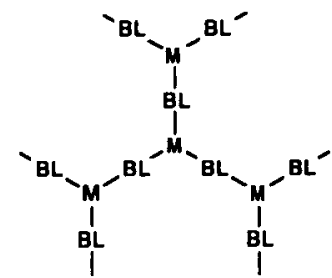


Table 1. Synthetic routes used for the synthesis of deca-, trideca-, and docosanuclear complexes. Original references $\mathrm{a}, \mathrm{b}$ etc are given in parentheses.

Decanuclear compounds

$\mathrm{M}_{a}\left[(\mu-\mathrm{BL}) \mathrm{M}_{b}(\mathrm{~L})_{2}\right]_{2} \mathrm{Cl}_{2}^{4+}+\mathrm{M}_{c}(\mathrm{BL})_{3}^{2+} \stackrel{3: 1}{\longrightarrow} \mathbf{M}_{c}\left\{(\mu-\mathrm{BL}) \mathrm{M}_{a}\left[(\mu-\mathrm{BL}) \mathrm{M}_{b}(\mathrm{~L})_{2}\right]_{2}\right\}_{3}^{20+}$

$\underline{10 \mathrm{~A}}(\mathrm{a}, \mathrm{b}) \quad \mathrm{M}_{a}=\mathrm{M}_{b}=\mathrm{M}_{c}=\mathrm{Ru}$

$10 \mathrm{~B}$ (a) $\mathrm{M}_{a}=\mathrm{M}_{b}=\mathrm{M}_{\mathrm{c}}=\mathrm{Ru}$

$\mathrm{BL}=2,3-\mathrm{dpp}$

$\mathrm{L}=$ bpy

$\underline{10 C}$ (a) $\quad M_{a}=M_{b}=R u, M_{c}=O s$

$\underline{10 \mathrm{D}}$ (a) $\mathrm{M}_{a}=\mathrm{M}_{b}=\mathrm{Ru}, \mathrm{M}_{c}=\mathrm{Os}$

$\underline{10 E}$ (a) $\quad M_{a}=R u, M_{b}=M_{c}=O s$

$\mathrm{BL}=2,3-\mathrm{dpp}$

$\mathrm{L}=$ biq

$\underline{10 F}$ (a) $\quad M_{a}=M_{c}=R u, M_{b}=O s$

$\mathrm{BL}=2,3-\mathrm{dpp}$

$\mathbf{L}=$ bpy

$\mathrm{BL}=2,3-\mathrm{dpp}$

$\mathrm{L}=$ biq

$\mathrm{BL}=2,3-\mathrm{dpp}$

$\mathrm{L}=$ bpy

$B L=2,3-d p p$

$\mathrm{L}=$ bpy

Tridecanuclear compounds

$\mathrm{M}\left[(\mu-\mathrm{BL}) \mathrm{M}(\mathrm{L})_{2}\right]_{2} \mathrm{Cl}_{2}^{4+}+\mathrm{M}[(\mu-\mathrm{BL}) \mathrm{M}(\mathrm{L})(\mathrm{BL})]_{3}^{8+} \stackrel{3: 1}{\longrightarrow} \mathrm{M}\left\{(\mu-\mathrm{BL}) \mathrm{M}(\mathrm{L})(\mu-\mathrm{BL}) \mathrm{M}\left[(\mu-\mathrm{BL}) \mathrm{M}(\mathrm{L})_{2}\right]_{2}\right\}_{3}^{26+}$
$\underline{13 A}$ (c)
$\mathbf{M}=\mathbf{R u}$
$B L=2,3-d p p$
$\mathrm{L}=$ bpy

Docosanuclear compounds

$\mathrm{M}\left[(\mu-\mathrm{BL}) \mathrm{M}(\mathrm{L})_{2}\right]_{2} \mathrm{Cl}_{2}^{4+}+\mathrm{M}\left[(\mu-\mathrm{BL}) \mathrm{M}(\mathrm{BL})_{2}\right]_{3}^{8+} \stackrel{6: 1}{\longrightarrow} \mathrm{M}\left\{(\mu-\mathrm{BL}) \mathrm{M}\left[(\mu-\mathrm{BL}) \mathrm{M}\left\{(\mu-\mathrm{BL}) \mathrm{M}(\mathrm{L})_{2}\right\}_{2}\right]_{2}\right\}_{3}^{44+}$

22A (d) $\quad M=R u$

$\mathrm{BL}=2,3-\mathrm{dpp}$

$\mathrm{L}=$ bpy

References: (a) - Denti et al (1992a); (b) - Serroni et al (1991); (c) Campagna et al (1992); (d) - Serroni et al (1992).

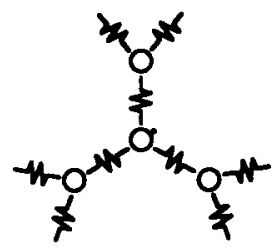

$+\mathrm{Cl}_{2} \mathrm{O}_{2 x^{\circ}}^{x^{\sigma_{1}}}$
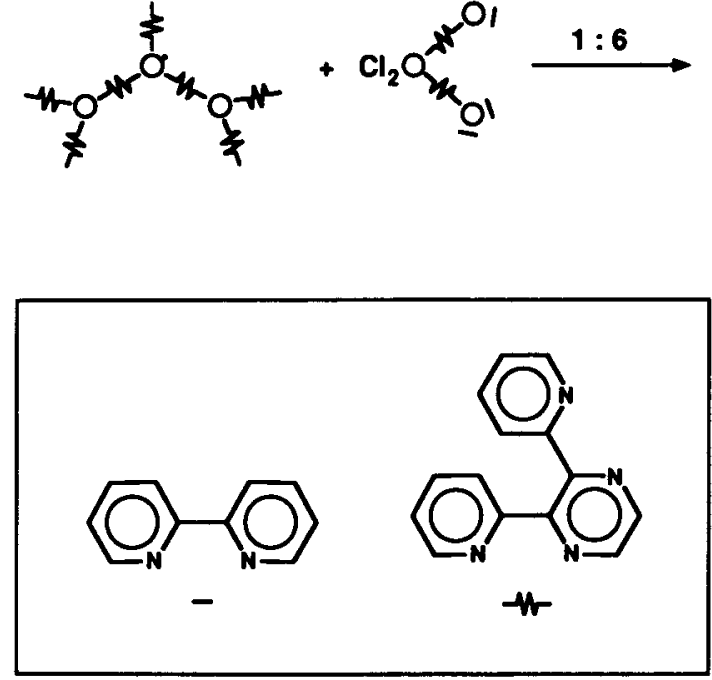

$-$

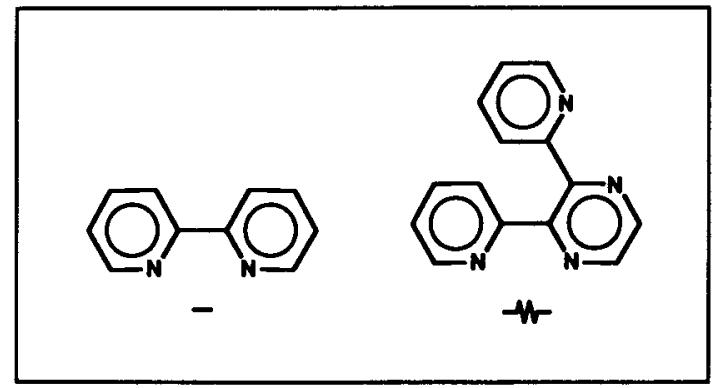

Scheme 2.

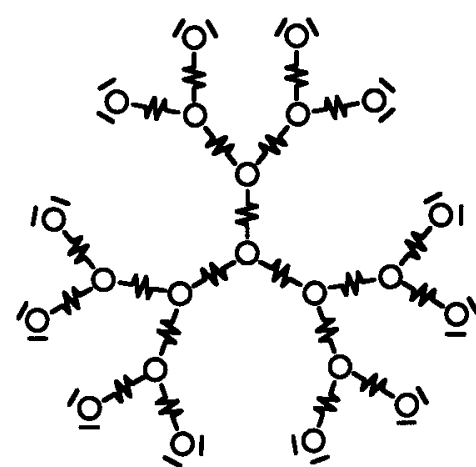




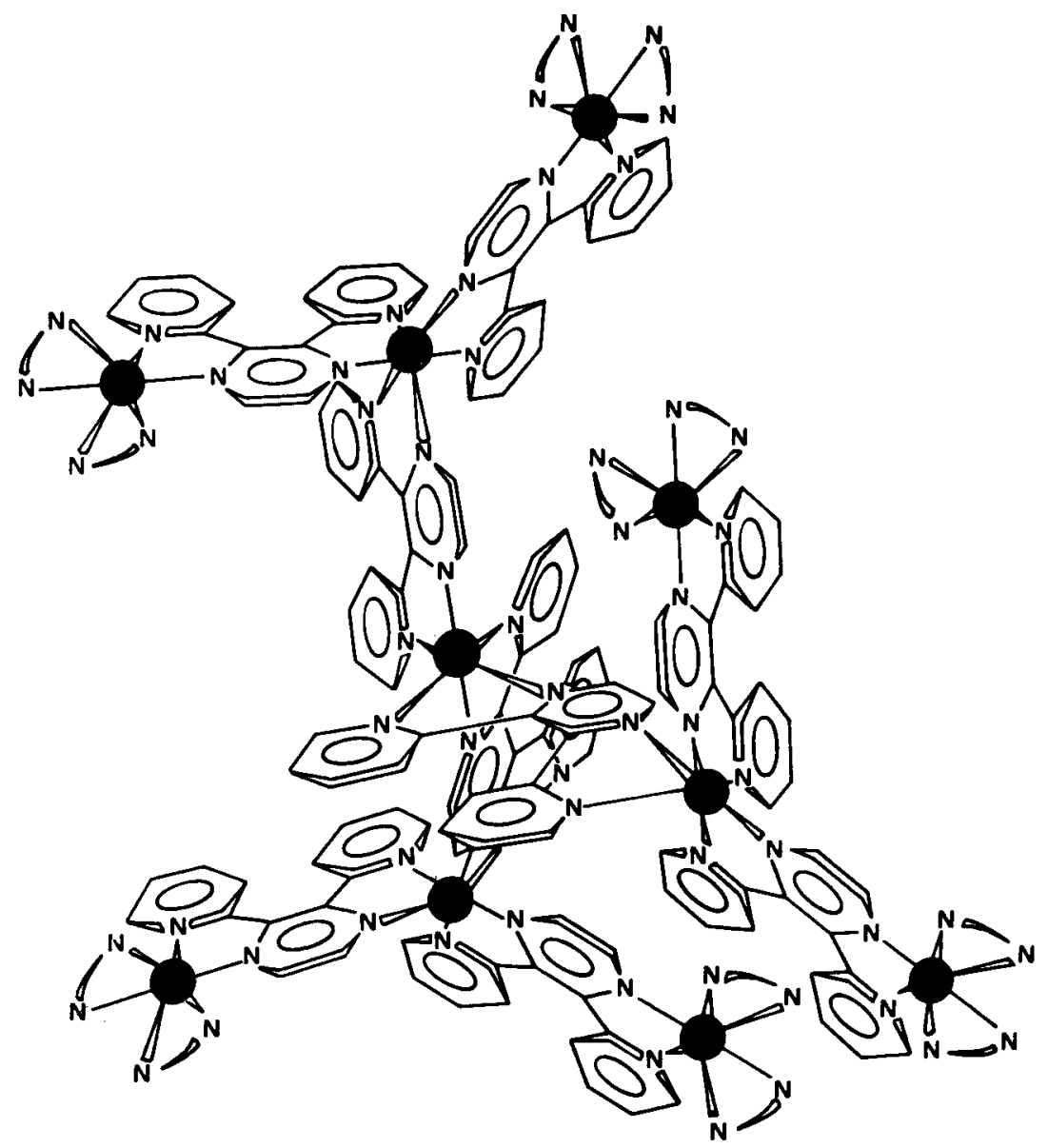

Figure 2. Schematic view of a decanuclear complex.

\section{General properties}

The compounds described in this paper are well-characterized supramolecular species made of a well-defined number of metal-containing components. They carry an overall positive charge that is twice the number of the metal atoms. Neglecting the $\mathrm{PF}_{6}^{-}$ counter ions, the docosanuclear compound $22 \mathrm{~A}$ ( 6 in scheme 2$)$ in made of 1090 atoms, has a molecular weight of 10890 daltons, and an estimated size of about $5 \mathrm{~nm}$. Besides the 22 metal atoms, it contains 24 terminal bpy ligands and 21, 2,3-dpp bridging ligands (Serroni et al 1992). Differences arising from the possible presence of isomeric species are not expected to be sizeable in the electrochemical and spectroscopic properties discussed below.

As one can understand from the schematic views shown in figures 2 and 3, species with high nuclearity exhibit a three-dimensional branching structure of the type shown by otherwise completely different compounds based on polyamidoamines or other organic components (for some recent papers see Shahlai and Hart 1990, Gopidas et al 1991, Hawker et al 1991, Newkome et al 1991 and Nagasaki et al 1992; see 


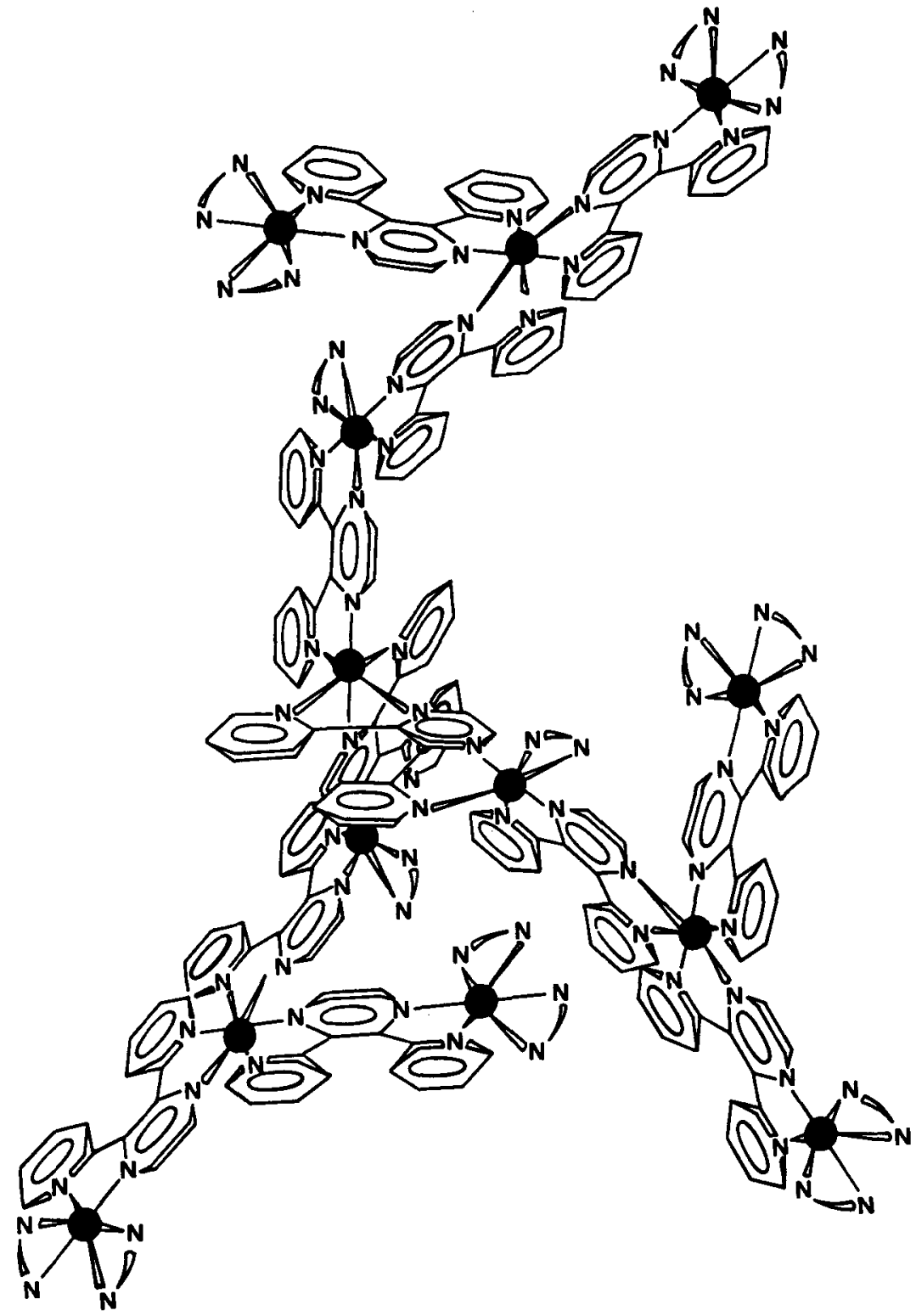

Figure 3. Schematic view of a tridecanuclear complex.

Tomalia et al 1990, for a comprehensive review). Therefore endo- and exoreceptor properties can be expected, which will be the object of future investigations.

We would like to stress that our complexes differ from most of the organic-type arborols or dendrimers prepared so far owing to two fundamental reasons: (i) each component exhibits valuable intrinsic properties such as absorption of visible (solar) radiation, luminescence, and redox levels at accessible potentials; (ii) by a suitable choice of the building blocks, different components can be placed in specific sites of the supramolecular array, as one can understand from figure 4 where the syntheses of 6 different decanuclear complexes, using different precursors, are schematized. In 
Dendritic polynuclear metal complexes
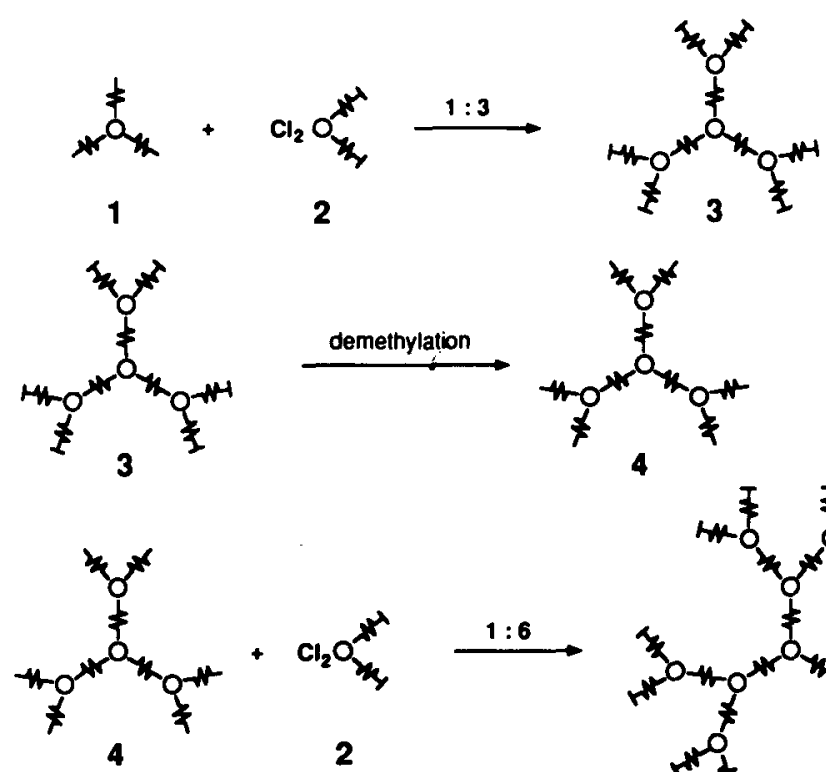

4
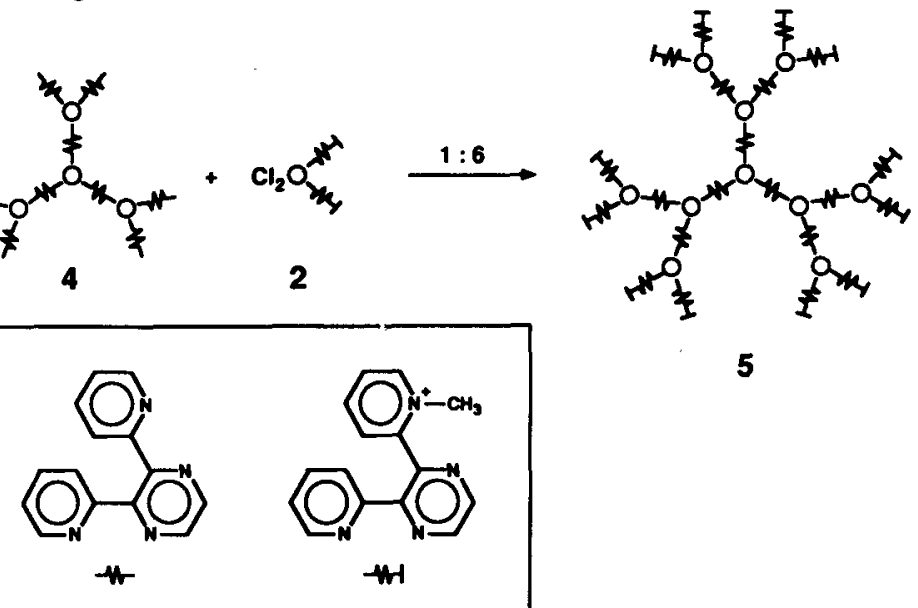

Scheme 3.

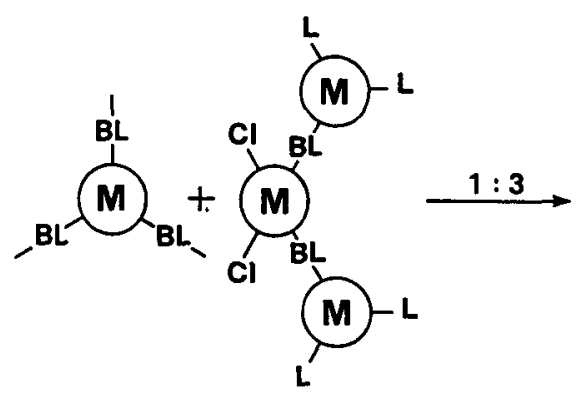<smiles>Ic1cc(I)cc([Tl])c1</smiles>

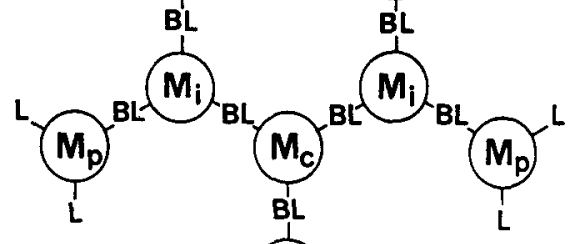

$\begin{array}{llll}M_{c} & M_{i} & M_{p} & L\end{array}$

10 A Ru Ru Ru bpy

10 B Ru Ru Ru biq

$10 \mathrm{C}$ Os Ru Ru bPy

$10 \mathrm{D}$ Os $\mathrm{Ru} R \mathrm{Ru}$ biq

10E Os Ru Os bPy

10F Ru Ru Os bpy
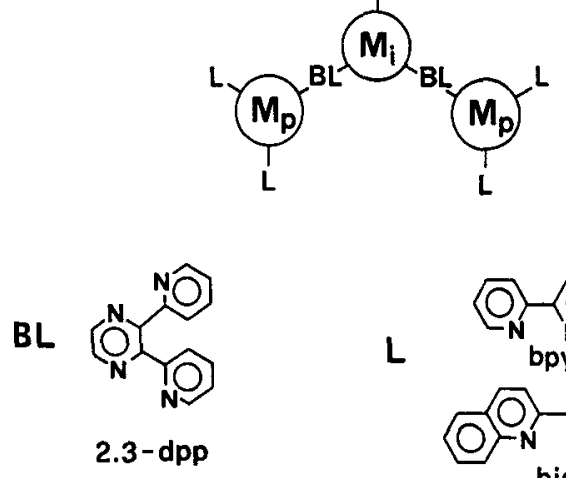

Figure 4. Scheme showing the synthetic control of the composition of decanuclear compounds. 
Table 2. Spectroscopic and electrochemical properties of selected polynuclear compounds."

\begin{tabular}{|c|c|c|c|c|c|c|}
\hline \multirow{2}{*}{\multicolumn{2}{|c|}{ Compounds }} & \multicolumn{2}{|c|}{ Absorption } & \multicolumn{2}{|c|}{ Emission } & \multirow{3}{*}{$\begin{array}{c}\begin{array}{c}\text { Electro- } \\
\text { chemistry }\end{array} \\
\begin{array}{c}E_{1 / 2}^{\mathrm{ox}}[n]^{\mathrm{c}} \\
V_{\text {vs SCE }}\end{array} \\
+1 \cdot 46[6]\end{array}$} \\
\hline & & \multirow{2}{*}{$\frac{\begin{array}{c}\lambda_{\max }^{b} \\
(\mathrm{~nm})\end{array}}{541}$} & \multirow{2}{*}{$\frac{\left(\begin{array}{c}\varepsilon \\
\mathrm{cm}^{-1}\end{array}\right)}{125000}$} & \multirow{2}{*}{$\begin{array}{l}\begin{array}{c}\lambda_{\max } \\
(\mathbf{n m})\end{array} \\
809\end{array}$} & \multirow{2}{*}{$\begin{array}{c}\begin{array}{c}\tau \\
\text { (ns) }\end{array} \\
55\end{array}$} & \\
\hline$\underline{10 \mathrm{~A}}$ & $\begin{array}{l}\operatorname{Ru}\{(\mu-2,3-d p p) \operatorname{Ru}[(\mu-2,3-d p p) \\
\left.\left.\quad \operatorname{Ru}(b p y)_{2}\right]_{2}\right\}_{3}^{20+}\end{array}$ & & & & & \\
\hline$\underline{10 B}$ & $\begin{array}{l}\operatorname{Ru}\{(\mu-2,3-d p p) \operatorname{Ru}[(\mu-2,3-d p p) \\
\left.\left.\quad \operatorname{Ru}(\text { biq })_{2}\right]_{2}\right\}_{3}^{20+}\end{array}$ & 555 & 109000 & 789 & 130 & $+1.62[6]$ \\
\hline$\underline{10 C}$ & $\begin{array}{l}\text { Os }\{(\mu-2,3-d p p) \operatorname{Ru}[(\mu-2,3-d p p) \\
\left.\left.\quad \operatorname{Ru}(b p y)_{2}\right]_{2}\right\}_{3}^{20+}\end{array}$ & 550 & 117000 & $\begin{array}{l}808 \\
860\end{array}$ & $\begin{array}{l}65 \\
d\end{array}$ & $\begin{array}{l}+1 \cdot 17[1] \\
+1.50[6]\end{array}$ \\
\hline $10 \mathrm{~F}$ & $\begin{array}{l}\mathrm{O}\{\{(\mu-2,3-\mathrm{dpp}) \mathrm{Ru}[(\mu-2,3-\mathrm{dpp}) \\
\left.\left.\mathrm{Os}(\mathrm{bpy})_{2}\right]_{2}\right\}_{3}^{20+}\end{array}$ & 563 & 140500 & $900^{\circ}$ & d & $\begin{array}{l}+1.05[6] \\
+1.39[1]\end{array}$ \\
\hline$\underline{13 \mathrm{~A}}$ & $\begin{array}{l}\operatorname{Ru}\{(\mu-2,3-d p p) \operatorname{Ru}(b p y)(\mu-2,3-d p p) \\
\left.\operatorname{Ru}\left[(\mu-2,3-d p p) \operatorname{Ru}(b p y)_{2}\right]_{2}\right\}_{3}^{26+}\end{array}$ & 544 & 133000 & 800 & 62 & $+1.50[9]^{8}$ \\
\hline $22 \mathrm{~A}$ & $\begin{array}{l}\operatorname{Ru}\{(\mu-2,3-d p p) \operatorname{Ru}[(\mu-2,3-d p p) \\
\left.\left.\operatorname{Ru}\left\{(\mu-2,3-d p p) \operatorname{Ru}(b p y)_{2}\right\}_{2}\right]_{2}\right\}_{3}^{44+}\end{array}$ & 542 & 202400 & 802 & d & $+1.52[12]$ \\
\hline
\end{tabular}

(a) Experiments in acetonitrile solution at room temperature, unless otherwise noted. Luminescence lifetimes are aerated values, unless otherwise stated. (b) Lowest energy ' ${ }^{1}$ MLCT band. (c) The numbers within brackets indicate the number of electrons exchanged. (d) Not measured. (e) At $90 \mathrm{~K}$ in $\mathrm{MeOH} / \mathrm{EtOH} \mathrm{4:1}$ (v/v) glassy matrix. (f) This wave exhibits a large separation between cathodic and anodic peaks $(\Delta E=180 \mathrm{mV})$. This suggests that there is a superposition of two closely spaced oxidation processes; the first one has been attributed to one-electron oxidation of six independent redox sites, and the second one to oneelectron oxidation of three independent redox sites.

other words, our arborols are species with a high "information" content and can therefore be exploited to perform valuable functions (vide infra).

The absorption, emission, and redox properties of some selected compounds are shown in table 2.

\section{Absorption spectra}

Since the interaction between the various metal-containing units is weak (vide infra) the absorption spectra of the oligonuclear complexes are, as one can expect, a combination of the absorption spectra of the single metal-containing components. When many components are present, the absorption spectra show very intense bands all over the UV and visible spectral region. For example, the spectra of the decanuclear compounds $10 \mathrm{~B}$ and $10 \mathrm{C}$ (figure 5) (Denti et al 1992a) show absorption bands with $\varepsilon$ up to $600,000 \mathrm{M}^{-1} \mathrm{~cm}^{-1}$ in the UV region and up to $140,000 \mathrm{M}^{-1} \mathrm{~cm}^{-1}$ in the visible region. The bands with maxima at 262 and $380 \mathrm{~nm}$ can be assigned to $\pi \rightarrow \pi^{*}$ transitions of the biq ligands, the band at $282 \mathrm{~nm}$ to $\pi \rightarrow \pi^{*}$ transitions of the bpy ligands, and the broad absorption in the $300-350 \mathrm{~nm}$ region to $\pi-\pi^{*}$ transitions of the biq and 2,3-dpp ligands. The broad bands observed in the visible region receive contributions from several types of metal-to-ligand charge-transfer (MLCT) transitions. The energies of these transitions depend on the nature of the donor metal ion, the acceptor ligand and the ancillary ligands. 


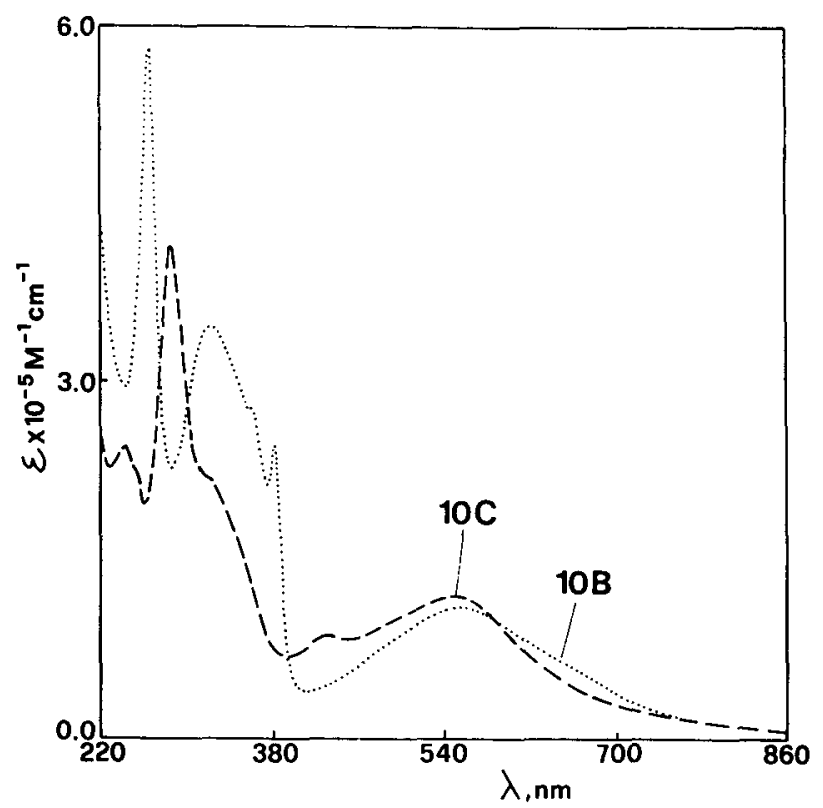

Figure 5. Absorption spectra of the decanuclear compounds $\underline{10 \mathrm{~B}}$ and $\underline{10 \mathrm{C}}$ in acetonitrile solution at room temperature.

\section{Electrochemical properties}

The mononuclear compounds of the $\mathrm{M}(\mathrm{BL})_{3-n}(\mathrm{~L})_{n}^{2+}$ series exhibit reversible redoxprocesses. On reduction, each $\mathrm{L}$ ligand is reduced twice and each BL ligand is reduced four times in the potential window $-0.5 /-3.1 \mathrm{~V}$ (Roffia et al 1993). The reduction potential of each ligand depends on its electronic properties and, to a smaller extent, on the nature of the metal and of the other ligands coordinated to the metal. It follows that on reduction of a polynuclear complex which contains several ligands (e.g., 21 ligands are present in the decanuclear complexes), an extremely complicated pattern with many overlapping peaks is observed. On oxidation of mononuclear complexes in the potential window $<+1.6 \mathrm{~V}$, only one peak is observed in the differential pulse voltammograms, which concerns the metal ion. The oxidation potential depends strongly on the nature of the metal ion (Os(II) is oxidized at less positive potentials compared to $\mathrm{Ru}(\mathrm{II})$ ) and, less dramatically, on the nature of the coordinated ligands. Because of the electronic properties of the isolated components (and of the stabilization of the LUMO of 2,3-dpp and 2,5-dpp on coordination to a second metal centre), it can be expected that for the metal-containing building blocks which are present in the synthesized polynuclear compounds the oxidation potential of the metal (and the energy of the lowest (luminescent) excited state) increases in the series Os(bpy $)_{2}(\mu-2,5-d p p)^{2+} \leqslant$ Os(bpy $)_{2}(\mu-2,3-d p p)^{2+}<$ Os(biq $)_{2}(\mu-2,5-d p p)^{2+} \leqslant$ $\operatorname{Os}(\mathrm{biq})_{2}(\mu-2,3-\mathrm{dpp})^{2+}<\mathrm{Os}(\mu-2,5-\mathrm{dpp})_{3}^{2+}<\mathrm{Os}(\mu-2,3-\mathrm{dpp})_{3}^{2+}<\operatorname{Ru}(\mathrm{bpy})_{2}(\mu-2,5-$ $\mathrm{dpp})^{2+} \leqslant \operatorname{Ru}(\mathrm{bpy})_{2}(\mu-2,3-\mathrm{dpp})^{2+}<\mathrm{Ru}\left(\mathrm{biq}_{2}\right)_{2}(\mu-2,5-\mathrm{dpp})^{2+} \leqslant \operatorname{Ru}\left(\right.$ biq $_{2}(\mu-2,3-\mathrm{dpp})^{2+}<$ $\operatorname{Ru}(\mathrm{bpy})(\mu-2,5-\mathrm{dpp})_{2}^{2+} \leqslant \operatorname{Ru}(\mathrm{bpy})(\mu-2,3-\mathrm{dpp})_{2}^{2+}<\operatorname{Ru}(\mu-2,3-\mathrm{dpp})_{3}^{2+}$.

It can also be expected (and it is confirmed by the experimental data, table 2) that in the polynuclear complexes the metal-metal interaction is non-negligible for metals coordinated to the same bridging ligand, whereas it is very weak for metals that do not share the same bridging ligand. Thus, equivalent units that are not directly 
connected are oxidized at the same potential. This allows us to control the number of electrons lost at certain potentials by placing in the supramolecular species the desired number of suitable, equivalent, and noninteracting units. For example, in compound $10 \mathrm{C}$ (figure 4), the differential pulse voltammogram (figure 6) shows an oxidation peak at $+1.17 \mathrm{~V}$, which is assigned to one-electron oxidation of the central $\mathrm{Os}^{2+}$ metal ion, and another peak at $+1.50 \mathrm{~V}$, which has the same bandwidth but six times higher intensity, that can be assigned to the independent one-electron oxidation of the six peripheral noninteracting $\mathrm{Ru}^{2+}$ ions. Oxidation of the three intermediate $\mathrm{Ru}^{2+}$ ions is further shifted towards more positive potentials and cannot be observed in the potential window examined. For $10 \mathrm{E}$, oxidation involves first the six peripheral $\mathrm{Os}^{2+}$ ions (which contain the stronger electron donor bpy ligand in their coordination sphere), and then the central one (figure 6).

In conclusion, the electrochemical data offer a fingerprint of the chemical and topological structure of the oligonuclear compounds. Furthermore, made-to-order synthetic control of the number of electrons exchanged at a certain potential can be achieved.

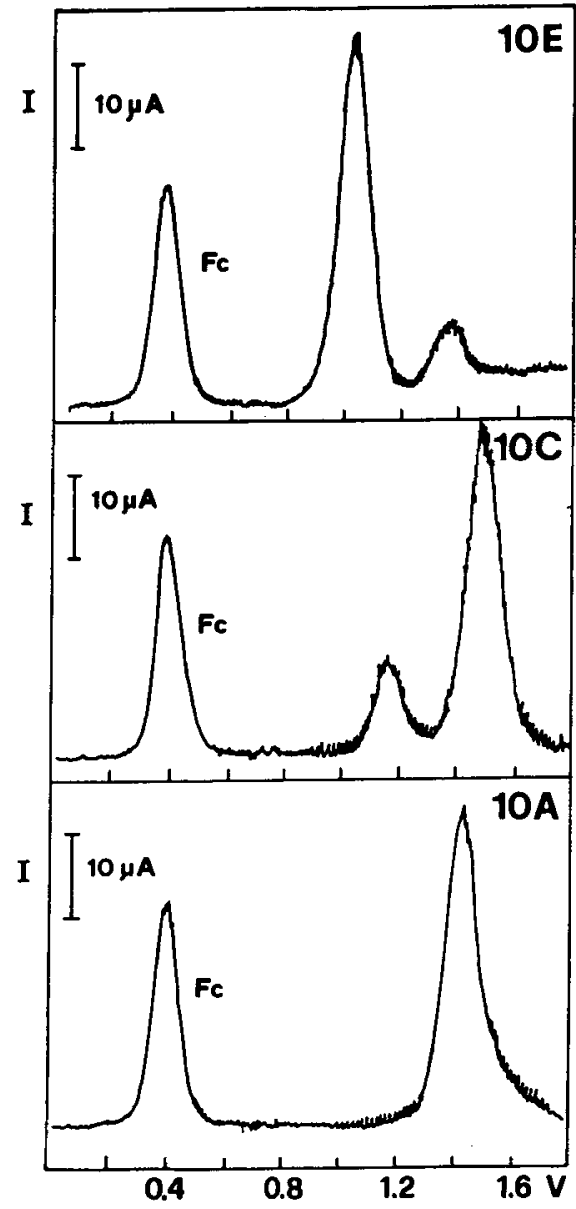

Figure 6. Oxidation patterns for some decanuclear complexes. Fc indicates the oxidation peak of ferrocene, used as an internal standard. 


\section{Luminescence}

Light excitation in the visible absorption bands populates ${ }^{1} \mathrm{MLCT}$ excited states in the various components. Investigations carried out on $\mathrm{Ru}(\mathrm{bpy})_{3}^{2+}$ with fast techniques indicate that the originally populated ${ }^{1} \mathrm{MLCT}$ excited states undergo relaxation to the lowest energy ${ }^{3}$ MLCT level in the subpicosecond time scale (Carrol and Bruss 1987; Bradley et al 1989; Yabe et al 1989; Cooley et al 1990). If this behaviour, as it seems likely, is of general validity for the various components of the polynuclear compounds, the actual result of light excitation is the population with unitary efficiency of the lowest energy ${ }^{3} \mathrm{MLCT}$ level of the component where light absorption has taken place. If each component were isolated, as it happens in mononuclear complexes, competition between radiative (luminescence) and radiationless decay to the ground state would account for the deactivation of the ${ }^{3}$ MLCT level, with an overall rate constant, measured from the luminescence decay, in the range $10^{6}-10^{8} \mathrm{~s}^{-1}$. All the members of the mononuclear $\mathrm{M}(\mathrm{BL})_{3-n}(\mathrm{~L})_{n}^{2+}$ family, in fact, display a characteristic luminescence both in rigid matrix at $77 \mathrm{~K}$ and in fluid solution at room temperature. When the components are linked together in a supramolecular array, electronic energy can be transferred from an excited component to an unexcited one even if the electronic interaction is weak. In most of the polynuclear compounds examined, only a luminescence band corresponding to the lowest energy ${ }^{3} \mathrm{MLCT}$ level is observed (table 2), indicating that energy transfer from upper-lying to lower-lying levels does occur (vide infra).

\section{Antenna effect}

The natural photosynthetic systems show that for solar energy conversion purposes supramolecular arrays are needed which absorb as much visible light as possible and are capable of channelling the resulting excitation energy towards a specific site of the array (antenna devices). The polynuclear metal complexes described in this paper are excellent light absorbers in the entire visible region. Furthermore, efficient energy transfer can take place between their components, as shown by the presence of only one luminescence band for compounds which contain more than one type of chromophoric units. The occurrence of energy transfer can be established by the quenching of the luminescence of the donor unit and the sensitization of the luminescence of the acceptor unit, and its efficiency can be estimated by comparing the absorption and excitation spectra. The energy levels involved in energy transfer are the lowest ${ }^{3} \mathrm{MLCT}$ excited state of each component. Because of these properties of the components and of the stabilization of the LUMO of 2,3-dpp and 2,5-dpp on coordination to a second metal centre, it can be expected that for the metal-containing building blocks which are present in the polynuclear compounds the energy of the lowest (luminescent) excited state increases (as does the oxidation potential, vide supra) in the series Os(bpy) $(\mu-2,5-\mathrm{dpp})^{2+} \leqslant \mathrm{Os}(\mathrm{bpy})_{2}(\mu-2,3-\mathrm{dpp})^{2+}<\mathrm{Os}(\mathrm{biq})_{2}(\mu-2,5-\mathrm{dpp})^{2+} \leqslant \mathrm{Os}(\mathrm{biq})_{2}(\mu-2,3-\mathrm{dpp})^{2+}<\mathrm{Os}$ $(\mu-2,5-\mathrm{dpp})_{3}^{2+}<\mathrm{Os}(\mu-2,3-\mathrm{dpp})_{3}^{2+}<\mathrm{Ru}(\mathrm{bpy})_{2}(\mu-2,5-\mathrm{dpp})^{2+} \leqslant \mathrm{Ru}(\mathrm{bpy})_{2}(\mu-2,3-\mathrm{dpp})^{2+}<$ $\operatorname{Ru}(\text { biq })_{2}(\mu-2,5-d p p)^{2+} \leqslant \mathrm{Ru}(\mathrm{biq})_{2}(\mu-2,3-\mathrm{dpp})^{2+}<\mathrm{Ru}(\mathrm{bpy})(\mu-2,5-\mathrm{dpp})_{2}^{2+} \leqslant \mathrm{Ru}(\mathrm{bpy})$ $(\mu-2,3-\mathrm{dpp})_{2}^{2+}<\mathrm{Ru}(\mu-2,3-\mathrm{dpp})_{3}^{2+}$.

By using the above guidelines, it is possible to design polynuclear complexes where the component(s) with the lowest energy excited state(s) is (are) located in the desired 
position(s) of the supramolecular structure. This allows a synthetic control of the direction(s) of energy migration after light absorption.

For the decanuclear compounds $10 \mathrm{~A}-10 \mathrm{~F}$, the directions along which energy transfer processes are exoergonic are schematically indicated by arrows in figure 7 (Denti et al 1992a). 10A displays a luminescence band at $809 \mathrm{~nm}$ that can be assigned straightaway to the peripheral (bpy) ${ }_{2} \mathrm{Ru} \rightarrow \mathrm{BL}$ excited states. The lack of luminescence at shorter wavelengths and the constancy of the luminescence quantum yield on changing the excitation wavelength indicate that the chromophoric groups based on the central and intermediate $\mathrm{Ru}^{2+}$ ions undergo an efficient deactivation to the peripheral $\mathrm{Ru}$-based units as expected because energy transfer is exoergonic in the direction from centre to periphery. $10 \mathrm{~B}$ exhibits exactly the same behaviour as $10 \mathrm{~A}$. For compounds $\underline{10 \mathrm{C}}$ and $\underline{10 \mathrm{D}}$, a broad luminescence band is observed at room temperature, with a shoulder on its low energy tail. The maxima of the luminescence bands almost coincide with those of the bands exhibited by $10 \mathrm{~A}$ and $\underline{10 \mathrm{~B}}$, respectively. The predominant emission can thus be assigned to the peripheral units. Substraction (after normalization) of the luminescence band of $10 \mathrm{~A}$ from that of $10 \mathrm{C}$ and of the band of $10 \mathrm{~B}$ from that of $10 \mathrm{D}$ yields a band with maximum at $\sim 860 \mathrm{~nm}$, as expected for the luminescence of a central Os unit. We conclude that, at room temperature, $10 \mathrm{C}$ and $10 \mathrm{D}$ emit from both the central and the peripheral units. Such behaviour is consistent with the fact that in $10 \mathrm{C}$ and $10 \mathrm{D}$ the lowest excited state of the intermediate Ru-based units lies at higher energy $\left(\sim 2000 \mathrm{~cm}^{-1}\right)$ than the lowest excited state of the peripheral units. Thus for $10 \mathrm{C}$ and $10 \mathrm{D}$ the two-step energy-transfer process from the peripheral units to the central one (where the lowest energy excited state of the supramolecular array is located) must be very slow since its first step is endoergonic by $\sim 2000 \mathrm{~cm}^{-1}$. Direct (through space) energy transfer from the peripheral to the central units is exoergonic but should be slow because of the large separating distance. A quantitative evaluation of the energy transfer efficiency from the peripheral to the central unit is difficult to make from luminescence quantum yield data because of the strong overlap between the absorption bands of the various units.

For $10 \mathrm{E}$ and $10 \mathrm{~F}$ the lowest excited states are localized on the peripheral (bpy) ${ }_{2} \mathrm{Os} \rightarrow \mathrm{BL}$ units which are expected to emit around $900 \mathrm{~nm}$. With infrared-sensitive equipment (Juris et al 1993) luminescence bands at 900 and $892 \mathrm{~nm}$ can in fact be observed for $10 \mathrm{E}$ and $10 \mathrm{~F}$, respectively. The lack of any $\mathrm{Ru}$-based luminescence for $10 \mathrm{~F}$ indicates a $100 \%$ efficient centre-to-periphery channelling of the excitation energy, as expected because of the energy gradient (figure 7). For $10 \mathrm{E}$, deactivation of the central Os-based unit by the peripheral ones should not occur because the first step of this process is endoergonic. The lack of observable luminescence from such a central unit may simply be due to the fact that most of the light, at any excitation wavelength, is absorbed by the much more numerous peripheral and intermediate units.

\section{Conclusion}

A synthetic strategy has been developed to obtain supramolecular dendritic structures of nanometric dimensions made of metal complex units capable of a high information content (light absorption, luminescence, redox activity). Specific metal and/or ligands 
<smiles>O=C(O)OC(=O)OC(=O)OC(=O)OC(=O)O</smiles>

$10 \mathrm{~A}$

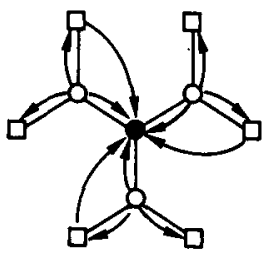

$10 \mathrm{D}$<smiles>O=C(O)OC(=O)OC(=O)OCc1ccccc1</smiles>

$10 \mathrm{~B}$

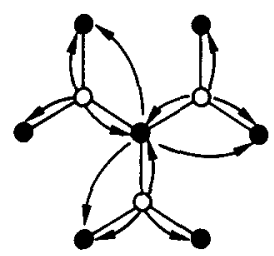

$10 \mathrm{E}$

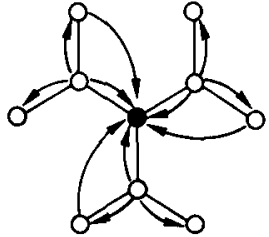

$10 \mathrm{C}$

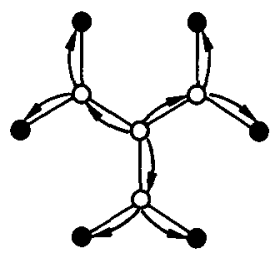

$10 \mathrm{~F}$

Figure 7. Energy migration patterns for some decanuclear compounds. Empty and full circles indicate $\mathrm{Ru}^{2+}$ and $\mathrm{Os}^{2+}$, respectively. In the peripheral positions, circles and squares indicate $\mathbf{M}(\mathrm{bpy})_{2}$ and $\mathbf{M}(\mathrm{biq})_{2}$ components, respectively. The arrows indicate the exoergonic energy transfer steps.

can be placed in predetermined sites of the supramolecular array by an appropriate choice of the building blocks. It is thus possible to design species where several important functions can be synthetically controlled. In particular, made-to-order control of the number of electrons lost at a certain potential and of the direction of electronic energy transfer can be achieved.

Because of their strong absorption in the visible spectral region and the possibility of predetermining the direction of energy migration, these compounds can be used as photochemical molecular devices (e.g., as antennas for harvesting solar energy) (Balzani et al 1987; Balzani and DeCola 1992, chap. 7). Because of the presence of several interacting and/or noninteracting redox centres, they are good candidates to play the role of multielectron-transfer catalysts.

\section{Acknowledgements}

We wish to thank V Cacciari, G Gubellini, L Minghetti and F Stillitani for technical assistance. This work was supported by the Ministero dell'Università e della Ricerca Scientifica e Tecnologica.

\section{References}

Anelli P L, Ashton P R, Ballardini R, Balzani V, Delgado M, Gandolfi M T, Goodnow T T, Kaifer A E, Philp D, Pietraskiewicz M, Prodi L, Reddington M V, Slawin A M Z, Spencer N, Stoddart J F, Vincent C and Williams D J 1992 J. Am. Chem. Soc. 114193 
Balzani V, Moggi L and Scandola F 1987 In Supramolecular photochemistry (ed.) V Balzani (Dordrecht: Reidel)

Balzani V and Scandola F 1991 Supramolecular photochemistry (Chichester: Horwood)

Bradley P C, Kress N, Hornberger B A, Dallinger R F and Woodruff W H 1989 J. Am. Chem. Soc. 1037441

Braunstein C H, Baker A D, Strekas T C and Gafney H D 1984 Inorg. Chem. 23857

Brewer K J, Murphy W R, Spurlin S R and Petersen J D 1986 Inorg. Chem. 25882

Campagna S, Denti G, Sabatino L, Serroni S, Ciano M and Balzani V 1989a J. Chem. Soc., Chem. Commun. 1500

Campagna S, Denti G, Sabatino L, Serroni S, Ciano M and Balzani V 1989b Gazz. Chim. Ital. 119415

Campagna S, Denti G, Serroni S, Ciano M and Balzani V 1991 Inorg. Chem. 303728

Campagna S, Denti G, Serroni S, Ciano M, Juris A and Balzani V 1992 Inorg. Chem. 312982

Carrol P J and Bruss L E 1987 J. Am. Chem. Soc. 1097613

Cooley L F, Bergquist P and Kelley D F $1990 \mathrm{~J}$. Am. Chem. Soc. 1122612

Denti G, Campagna S, Sabatino L, Serroni S, Ciano M and Balzani V 1990a Inorg. Chem. 294750

Denti G, Campagna S, Sabatino L, Serroni S, Ciano M and Balzani V 1990b Inorg. Chim. Acta 176175

Denti G, Campagna S, Sabatino L, Serroni S, Ciano M and Balzani V 1991a In Photochemical conversion and storage of solar energy (eds) E Pellizzetti and M Schiavello (Dordrecht: Kluwer) p. 27

Denti G, Serroni S, Campagna S, Ciano M and Balzani V 1992a J. Am. Chem. Soc. 1142944

Denti G, Serroni S, Campagna S, Juris A and Balzani V 1993 Mol. Cryst. Liquid. Cryst. (in press)

Denti G, Serroni S, Campagna S, Juris A, Ciano $M$ and Balzani V 1992b In Perspectives in coordination chemistry (eds) A F Williams, C Floriani and A Merbach (Basel: VCH) p. 153

Denti G, Serroni S, Campagna S, Ricevuto V and Balzani V 1991b Inorg. Chim. Acta 182127

Denti G, Serroni S, Campagna S, Ricevuto V and Balzani V 1991c Coord. Chem. Rev. 111227

Denti G, Serroni S, Campagna S, Ricevuto V, Juris A, Ciano M and Balzani V 1992c Inorg. Chim. Acta 198-200 507

Gopidas K R, Leheny A R, Caminati G, Turro N J and Tomalia D A 1991 J. Am. Chem. Soc. 1137335

Hawker C J, Lee R and Fréchet J M J 1991 J. Am. Chem. Soc. 1134583

Juris A, Balzani V, Barigelletti F, Campagna S, Belser P and von Zelewsky A 1988 Coord. Chem. Rev. 8485

Juris A, Balzani V, Campagna S, Denti G, Serroni S, Frei G and Güdel H U 1993 Inorg. Chem. (in press)

Kalyanasundaram K 1991 Photochemistry of polypyridine and porphyrin complexes (London: Academic Press)

Lehn J -M 1990 Angew. Chem., Int. Ed. Engl. 291304

Nagasaki T, Ukon M, Arimori S and Shinkai S 1992 J. Chem. Soc., Chem. Commun. 608

Newkome G R, Moorefield C N, Baker G R, Saunders M J and Grossman S H 1991 Angew. Chem., Int. Ed. Engl. 301178

Roffia S, Marcaccio M, Paradisi C, Paolucci F, Balzani V, Denti G, Serroni S and Campagna S 1993 Inorg. Chem. 323003

Schneider H J and Durr H (eds) 1991 Frontiers in supramolecular organic chemistry and photochemistry (Weinheim: VCH)

Serroni S, Denti G, Campagna S, Ciano M and Balzani V 1991 J. Chem. Soc., Chem. Commun. 944 Serroni S, Denti G, Campagna S, Juris A, Ciano M and Balzani V 1992 Angew. Chem., Int. Ed. Engl. 311493

Shahlai K and Hart H 1990 J. Am. Chem. Soc. 1123687

Tomalia D A, Naylor A M and Goddard W A III 1990 Angew. Chem., Int. Ed. Engl. 29138

Vögtle F 1991 Supramolecular chemistry (Chichester. John Wiley)

Whitesides G M, Mathias J P and Seto C T 1991 Science 2541312

Yabe T, Anderson D R, Orman L K, Chang Y J and Hopkins J B 1989 J. Phys. Chem. 932302 